\title{
Gastroözefageal Reflü Hastalığı ile Tıkınırcasına Yeme Bozukluğu Arasındaki İlișki
}

\section{The Relationship Between Gastroesophageal Reflux Disease and Binge Eating Disorder}

\author{
iD Akın Çalışır ${ }^{1}$, iD Saliha Çalışır², iD Mustafa Şahin ${ }^{1}$, iD Hasan Maden³, iD Hüsnü Alptekin
}

${ }^{1}$ Selçuk Üniversitesi Tıp Fakültesi Hastanesi Genel Cerrahi Kliniği, Konya, Türkiye

${ }^{2}$ Meram Devlet Hastanesi Ruh Sağlığı ve Hastalıkları Kliniği, Konya, Türkiye

${ }^{3}$ Gölköy Devlet Hastanesi, Ordu, Türkiye

$\ddot{O} z$

Amaç: Gastroözefageal reflü hastalı̆ı̆, asit mide içeriğinin efor sarf etmeksizin özefagusa geri gelmesi ile ortaya çıkan bir hastalıktır ve günümüzde beslenme alışkanlıklarınıı değişmesiyle sıklığı giderek artmaktadır. Bu çalışma ile en sık görülen yeme bozukluğu olan tıkınırcasına yeme bozukluğu ile gastroözefageal reflü hastalı̆ı arasındaki ilișki olup olmadığı ortaya konulacaktır.

Metod: 2011 ve 2018 yılları arasında gastroözefageal reflü hastalığı nedeniyle 24 saatlik pH monitörizasyon işlemi yapılan hastaların dosyaları geriye dönük olarak incelendi. Çalışmaya katıımayı kabul eden 305 hastaya ve aynı sayıda sağlıkı kontrol grubuna tıkınarcasına yeme bozukluğu tanı anketi yapıldı. Her iki grup arasında demografik veriler ve tıkınırcasına yeme bozukluğu tanısı açısından karşılaştırma yapıldı. Ayrıca tıkınırcasına yeme bozukluğu tanısı konulan hastaların 24 saatlik pH monitörizasyon verileri diğer reflü hastaları ile karşılaştırıldı.

Sonuç: Vücut kitle indeksi yüksekliği ve sigara kullanımı, gastroözefagal reflü grubunda daha yüksek bulundu. Yaş ve cinsiyet açısından her iki grup arasında anlamlı bir fark izlenmedi. Tıkınırcasına yeme bozukluğu olan hastalarda toplam reflü zamanı, uzun reflü periyod sayısı, en uzun reflü ve DeMeester skoru anlamlı derecede yüksek bulundu.

Anahtar kelimeler: Gastroözefageal reflü, Tıkınırcasına yeme, 24-h pH monitörizasyonu

Abstract

Purpose: Gastroesophageal reflux disease is a common condition that is characterized with esophageal mucosal injury secondary to gastric acid reflux. The aim of this study is to reveal whether there is a relationship between binge eating disorder and gastroesophageal reflux disease.

Methods: Patients with gastroesophageal reflux disease who underwent 24-h esophageal pH monitoring between 2016 and 2018 were evaluated retrospectively. Binge eating disorder diagnosis questionnaire was applied to 305 patients of these who agreed to participate in the study. The same questionnaire was applied to the control group consisting of the same number of healthy participants. A comparison was made between both groups in terms of demographic data and diagnosis of binge eating disorder. Also, 24-hour $\mathrm{pH}$ monitoring data of the patients diagnosed with binge eating disorder were compared with other reflux patients.

Results: In the gastroesophageal reflux group, smoking incidence and higher body mass index was significantly more common. There was no significant difference between the two groups in terms of age and gender. Total reflux time, number of long reflux periods, longest reflux and DeMeester score were found to be significantly higher in patients with binge eating disorder.

Key Words: Gastroesophageal reflux, Binge eating, 24-h pH monitor

Yazışma Adresi: Akın Çalışır, Selçuk Üniversitesi Tıp Fakültesi Hastanesi Genel Cerrahi Kliniği, Konya, Türkiye.

E-Posta: dracalisir@gmail.com

Alınma tarihi: 16.03.2021 / Kabul tarihi: 26.03.2021 / Yayımlanma tarihi: 15.12.2021

Gastroözefageal Reflü Ve Tıkınırcasına Yeme - Çalışır ve ark. 


\section{Giriş}

Gastroözefageal reflü (GÖR), fizyolojik antireflü bariyerinin yetersiz kalması sonucu mide içeriğinin efor harcamaksızın özefagusa geri gelmesidir ve günde 10-50 kereye kadar olabilen fizyolojik bir olaydır (1). Fizyolojik reflü asemptomatiktir çünkü sıklığı ve süresi semptom oluşturacak düzeyde değildir. Çeşitli sebeplerle reflü periyotlarının sıklığının ve sayısının artması, reflü sürelerinin uzamas1 nedeniyle hastalarda retrosternal yanma gibi şikayetler ortaya çıkar. Bu duruma gastroözefageal reflü hastalığı (GÖRH) denir (2). Günümüzde değişen beslenme alışkanlıkları ve obezitenin artması nedeniyle GÖRH görülme sıklı̆̆ gittikçe artmaktadır. Batı toplumlarında prevalansı \%10-20'dir. Ülkemizde de benzer şekilde \%20’ler civarında görülmektedir (3-6).

Tıkınırcasına yeme bozukluğu (TYB), bir bireyin aynı zaman diliminde ve aynı koşullarda yiyebileceğinden çok daha fazla miktarda yiyeceği kısa bir süre içinde tükettiği, yemek yeme davranışını dizginleyemediği ve aşırı miktarlarda yemek yeme davranışının tekrar ettiği, bulimia nevrozada görülen uygunsuz kompansatuar davranışların (kendini kusmaya zorlama, laksatif kötüye kullanımı gibi) bulunmadığı bir yeme bozukluğudur $(7,8)$. TYB yetişkinlerde en s1k görülen yeme bozukluğudur ve yaşam boyu prevalansı \%1.9' dur (9). TYB ile obezite gelişmesi arasında ilişki olduğunu gösteren çalışmalar bulunmaktadır (10-12). Ayrıca diyabet, hipertansiyon, artrit, uyku problemleri, astım ve gastrointesitnal semptomlar ( dispepsi, ülser, irritabl barsak sendromu gibi) ile de ilişkili bulunmuştur (13)

Bu çalışma ile TYB ile GÖRH arasında bir ilişki olup olmadığının araştırılması amaçlanmıştır.

\section{Gereç ve Yöntem}

\section{Katılımcılar ve Grupların belirlenmesi}

Çalışma, Selçuk Üniversitesi Tıp Fakültesi Girişimsel Olmayan Klinik Araştırmalar Etik Kurulununn onayı alınarak yapılmıştır (2018/404). Çalışma, GÖRH grubu ve Kontrol grubu olmak üzere iki grup olarak planlandı. Ocak 2011- Aralık 2018 tarihleri arasında Selçuk Üniversitesi Tıp Fakültesi Hastanesi Genel Cerrahi Endoskopi Ünitesi'nde GÖRH nedeniyle 24 saatlik pH monitörizasyon işlemi yapılan hastaların dosyaları geriye dönük olarak incelendi. Hastaların dosyalarındaki iletişim numaralı ve eposta adresleri aracılığıyla hastalara ulaşıldı. Tıkınırcasına Yeme Bozukluğu Tanı Ölçütleri Anketini doldurmayı kabul eden ve geri dönüş yapan, 18-65 yaş aralığındaki, antireflü cerrahisi geçirmemiş, özefageal kitle veya malignite şüphesi olmayan, özefageal motilite bozukluğu olmayan, endoskopik değerlendirme ile GÖRH tanısı koyulmuş hastalar, GÖRH grubuna dahil edilerek çalışmaya alındı. Kontrol grubuna ise GÖRH olmayan, 18-65 yaş aralığındaki sağlık bireyler dahil edildi. 18 yaş altında veya 65 yaş üzerinde olan hastalar, özefagus veya üst gastrointestinal sistem cerrahisi öyküsü olan, özefageal kitle ve motilite bozukluğu olan hastalar çalışmaya dahil edilmedi.

\section{GÖRH ve Tıkınırcasına Yeme Bozukluğu Tanısı}

GÖRH tanıs1, tipik semptomların varlığı ve yapılan gastroskopide özefajit bulguları olması ile koyuldu. Kontrol grubuna dahil edilen katılımcılarda, reflü tanı anketi (Reflux Diagnostic questionnaire = RDQ) kullanılarak GERH olmadığı doğrulandı. RDQ, son 4 haftada içerisinde olan reflü, asit regürjitasyonu, mide yanmas1, substernal ağrı semptomlarının değerlendirmesinde kullanılan bir ankettir ve birçok çalışmada GÖRH tanısında kullanılmıştır $(14,15)$. Bu anketle semptomların sıklığını ve şiddetini değerlendirmek için ayrı ayrı 0 ile 20 arasında skorlama yapılır. Bu skorun $>12$ olması ile GÖRH tanıs1 koyulur (16). Bu nedenle RDQ $<12$ olan bireylerde GERH olmadığı kabul edildi ve bu kişeler kontrol grubuna dahil edildi.

TYB tanis1, DSM-5 (Diagnostic and Statistical Manual of Mental Disorders, Fifth Edition) Tıkınırcasına Yeme Bozukluğu Tanı ölçütleri anketi yapılarak koyuldu (8)(Tablo 1).

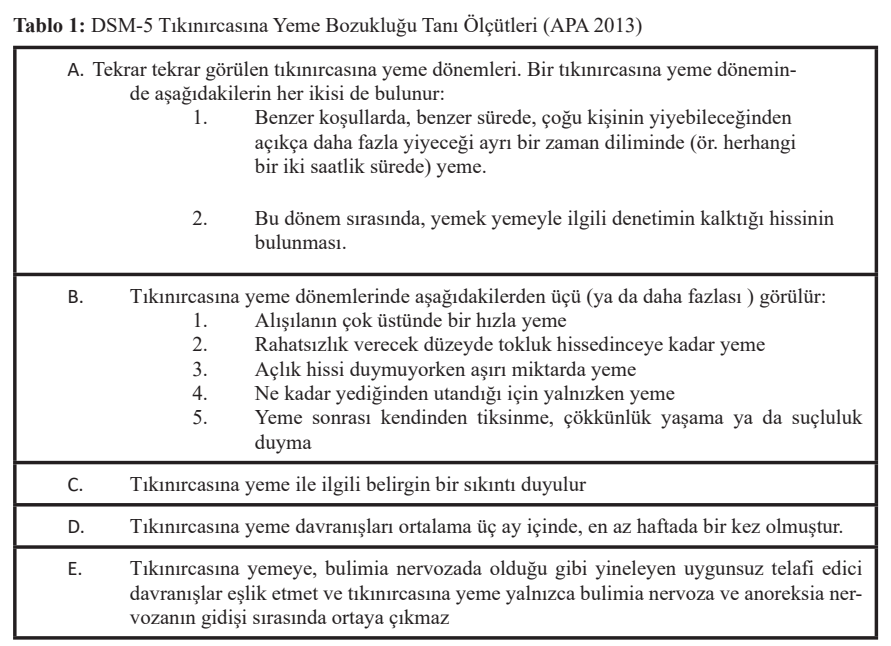

Özefagusa asit reflüsünü kantitatif olarak değerlendirmek için 24 saatlik $\mathrm{pH}$ monitörizasyon tetkiki verileri kullanıldı. Bu sayede GÖRゆlan hastalarda TYB' nun reflü üzerine olan etkileri daha objektif olarak değerlendirildi. Bu işlem ile, transnazal yolla alt özefagus sfinkterinin $5 \mathrm{~cm}$ proksimaline yerleştirilen $\mathrm{pH}$ katateri sayesinde 24 saat boyunca olan patolojik reflü hareketleri saptanıp kaydedildi. Sonuçlar, DeMeester ve ark. tarafından geliştirilen ve $\mathrm{pH}$ monitörizasyonu verilerinin değerlendirilmesi için oluşturulan skorlama sistemini kullanılarak değerlendirildi (17).

\section{Çalışma protokolü}

Çalışmaya alınan katılımcıların yaş, cinsiyet, vücut kitle indeksi (VKİ), sigara kullanımı gibi demografik verileri kaydedildi. GÖRH grubundaki hastalara e-posta veya telefon aracılığıyla, Kontrol grubundaki katılımcılara ise yüz yüze görüşme yapılarak TYB tanı ölçütleri anketi uygulandı. Ayrıca GÖRH grubundaki hastaların 24 saatlik pH monitörizasyon işlemi ile elde edilen toplam reflü zamanı, reflü periyod sayıs1, uzun reflü periyod sayısı, en uzun reflü ve DeMeester skorları kaydedildi.

\section{İstatistiksel analiz}

İstatistiksel analizde Statistical Package for the Social Sciences software package (SPSS; version 15.0; SPSS Inc., Chicago, Illinois, USA) programı kullanıldı. Devamlı veriler ortalama \pm standart sapma, kategorik veriler ise sayı ve yüzde ile sunuldu. Gruplar arası devamlı verilerin karşılaştırılmasında bağımsız t-testi, kategorik verilerin karşılaştırılmasında ise ki-kare testi kullanıldı. p değeri $<0,05$ anlamlı olarak kabul edildi.

\section{Sonuçlar}

Gastroözefageal Reflü Ve Tıkınırcasına Yeme - Çalışır ve ark. 
Çalışmaya dahil edilen süre içerisinde 24 saatlik pH monitörizasyon işlemi yapılan 421 hastanın dosyaları incelendi. 49 hastaya, eksik veya değişmiş iletişim bilgileri nedeniyle ulaşılamadı. 67 hasta ise gönderilen ankete geri dönüş yapmadı veya anketi doldurmayı kabul etmedi. TYB tanı ölçütleri anketini cevaplayan 305 hasta çalışmaya alındı. Kontrol grubu şartlarına uyan 305 katılımcıya da TYB tanı ölçütleri anketi uygulandı.

Gruplar arasında yaş ve cinsiyet açısından fark izlenmedi. GÖRH grubunda ortalama VKİ $27,96 \pm 5,71 \mathrm{~kg} / \mathrm{m}^{2}$, kontrol grubunda ise ortalama $24,48 \pm 6,88 \mathrm{~kg} / \mathrm{m}^{2}$ olarak izlendi. Gruplar aras1 sigara kullanımı değerlendirildiğinde GÖRH grubunda sigara kullanımı $\% 34,8$ olarak bulunurken, kontrol grubunda bu oran \%23,6 olarak saptand1. GÖRH grubunda VKİ ve sigara kullanımı anlamlı derecede yüksek bulundu ( sırasıyla $p=0,01$ ve $p<0,01$ ). Yaş, VKİ, cinsiyet, sigara kullanımı verilerine göre grupların değerlendirilmesi tablo 2'de özetlendi.

Tablo 2: Yaş, VKİ, cinsiyet, sigara kullanımına göre grupların karşılaştırılması

\begin{tabular}{|c|c|c|c|c|}
\hline & & GÖRH & KONTROL & $\mathbf{p}$ \\
\hline \multicolumn{2}{|l|}{ Yaş a } & $43.28 \pm 16.10$ & $41.47 \pm 16.57$ & $0.17^{*}$ \\
\hline \multicolumn{2}{|c|}{ VKİ $\left(\mathrm{kg} / \mathrm{m}^{2}\right)^{\mathrm{a}}$} & $27.96 \pm 5.71$ & $24.48 \pm 6.88$ & 0.01 * \\
\hline \multirow[t]{2}{*}{ Cinsiyet } & Erkek ${ }^{b}$ & $166(\% 54.4)$ & $145(\% 47.5)$ & \multirow[t]{2}{*}{$0.08^{* *}$} \\
\hline & Kadın $^{\text {b }}$ & $139(\% 45.6)$ & $160(\% 52.5)$ & \\
\hline \multicolumn{2}{|c|}{ Sigara kullanımı ${ }^{\mathrm{b}}$} & $106(\% 34.8)$ & $72(\% 23.6)$ & $<0.01^{*}$ \\
\hline \multicolumn{5}{|c|}{${ }^{\mathrm{a}}$ ortalama \pm standart sapma } \\
\hline \multicolumn{5}{|l|}{${ }^{\mathrm{b}} \mathrm{n}(\%)$} \\
\hline \multicolumn{5}{|c|}{ "bağımsız t testi } \\
\hline \multicolumn{5}{|c|}{${ }^{" *}$ ki kare testi } \\
\hline \multicolumn{5}{|c|}{$\mathrm{p}<0.05$ anlamlı olarak kabul edilmiștir. } \\
\hline
\end{tabular}

Çalışmaya alınan toplam 610 kişden $11(\% 1,8)$ 'i TYB tanı kriterlerini karşılamaktaydı. TYB açısından gruplar karşılaştırıldığında ise GÖRH grubunda $9(\% 3)$, kontrol grubunda ise $2(\% 0,7)$ kişide TYB olduğu izlendi ve bu fark istatistiki açıdan anlamlı olarak değerlendirildi $(\mathrm{p}=0,03)$.

GÖRH grubundaki, TYB olan ve olmayan hastaların 24 saatlik pH monitörizasyon işlemi ile elde edilen sonuçlarının karşılaştırılması tablo 3'de gösterildi.

Tablo 3: TYB olan ve olmayan hastaların 24 saatlik pH monitörizasyon işlemi ile elde edilen sonuçları karşılaştırılması

\begin{tabular}{|c|c|c|c|}
\hline & TYB + & TYB - & $\mathbf{p}$ \\
\hline Toplam reflü zamanı & $7.22 \pm 1.56$ & $5.64 \pm 1.26$ & $<0.01$ \\
\hline Reflü periyod sayısı & $61.33 \pm 15.01$ & $55.22 \pm 18.76$ & 0.33 \\
\hline Uzun reflü periyod sayısı & $7.44 \pm 2.18$ & $3.77 \pm 1.0$ & $<0.01$ \\
\hline En uzun reflü & $24.33 \pm 8.03$ & $10.88 \pm 4.15$ & $<0.01$ \\
\hline DeMeester skoru & $25.44 \pm 13.06$ & $13.35 \pm 6.70$ & $<0.01$ \\
\hline \multicolumn{4}{|c|}{ TYB + : tıkınırcasına yeme bozukluğu olan hastalar } \\
\hline \multicolumn{4}{|c|}{ TYB - : tıkınırcasına yeme bozukluğu olmayan hastalar } \\
\hline \multicolumn{4}{|c|}{ Verilerin değerlendirilmesinde bağımsız $t$ testi kullanılmıştır. } \\
\hline \multicolumn{4}{|c|}{ Veriler ortalama \pm standart sapma olarak verilmiştir. } \\
\hline $\mathrm{p}<0.05$ anlamlı olarak kab & & & \\
\hline
\end{tabular}

TYB olan hastalarda toplam reflü zamanı 24 saatte ortalama $\% 7,22 \pm$

Gastroözefageal Reflü Ve Tıkınırcasına Yeme - Çalışır ve ark.
1,56 olarak saptanırken, bu oran TYB olmayanlarda ortalama $\% 5,64$ $\pm 1,26$ olarak bulundu $(\mathrm{p}<0,01)$.

Reflü periyod sayısı karşılaştırıldı̆̆ında ise, TYB olanlarda ortalama $61,33 \pm 15.01$ reflü periyodu izlenirken, TYB olmayanlarda ise bu sayı ortalama $55,22 \pm 18,76$ olarak bulundu $(\mathrm{p}=0,33)$.

TYB olan GÖRH grubu hastalarında uzun süren reflü periyodu sayıs1 ortalama $7,44 \pm 2,18$, TYB olmayanlarda ise ortalama $3,77 \pm 1$ olarak bulundu $(\mathrm{p}<0,01)$.

En uzun süren reflü periyodu TYB olanlarda ortalama 24,33 $\pm 8,03$ $\mathrm{dk}$ olarak bulunurken TYB olmayanlarda ortalama 10,88 $\pm 4,15 \mathrm{dk}$ olarak bulundu $(\mathrm{p}<0.01)$.

DeMeester skoru karşılaştırmasında, TYB olan hastalarda bu skor ortalama $25,44 \pm 13,06$, TYB olmayanlarda ise ortalama $13,35 \pm 6,70$ olarak bulundu.

\section{Tartıșma}

GÖRH, multifaktöriyel bir hastalıktır. Ancak etyolojik faktörlerin tümünde, mide ile özefagus arasındaki normal antireflü bariyer olan özefagogastrik bileşkenin fonksiyonunun geçici ya da kalıcı olarak bozulması söz konusudur. Tek başına bu antireflü bariyerin bozulmasına sebep olan en sik sebep alt özefagus sfinkter (AÖS) fonksiyon bozukluğudur (2). Bunun dışında hastalığın patogenezinde azalmış özefagus motilitesi, bozulmuş özefageal mukozal defansif faktörler ve gecikmiş mide boşalması da bulunmaktadır (18). Ayrıca yapılan çalışmalarda GÖRH nın obezite, metabolik sendrom, uyku apnesi ve yaşlanma ile de ilişkili olduğu gösterilmiştir (19-21).

GÖRH, toplumda s1k görülen ve tedavi edilmediği takdirde uzun dönemde ciddi morbiditelere sebep olabilen bir hastalıktır. Etyolojisinde birçok faktör rol oynamaktadır. GÖRH etyolojisi ve risk faktörleri ile ilgili yapılan çalışmalarda cinsiyet açısından yapılan değerlendirmelerde birbiri ile çelişen sonuçlar bulunmaktadır (2224). Ülkemizde yapılan bir çalışmada ise GÖRH açısından kadınerkek arasında bir farklılık izlenmemiştir (25). Bizim çalışmamızda da benzer şekilde GÖRH ile kontrol grubu arasında cinsiyet açısından anlamlı bir farklılık izlenmedi. Obezite ve sigara kullanımı da GÖRH riskini artıran faktörler olarak tanımlanmıştır (26). Bizim çalışmamızda da literatürle benzer olarak GÖRH grubunda sigara kullanım oranı daha yüksek bulundu. Ayrıca GÖRH grubundaki hastaların VKI'leri kontrol grubu ile kıyaslandığında anlamlı derecede yüksek bulundu.

GÖRH ile oluşan reflü özefajiti, Barret metaplazisine ve özefagus kanserine ilerleyebilir (27). Özefagus kanseri olan hastalarda yapılan bir araştırmada, bu hastalarda hızlı yeme, mide tamamen doluncaya kadar yeme ve çok sıcak yiyecekler yeme gibi yeme alışkanlıklarının sık görüldüğü bulunmuştur (16). Ayrıca midenin tam dolu, ve distandü olmasının AÖS tonusunu azalttığı gösterilmiştir (28). Bu durum, yeme alışkanlıklarının GÖRH ve bununla ilişkili ilerleyen patolojilerin oluşmasında etkili olduğunu göstermektedir. GÖRH ve beslenme ile ilgili olarak yapılan çalışmalarda genellikle yiyeceklerin içeriği ve kalori değerleri ile hastalığın patofizyolojisi ve semptomları arasındaki ilişki ortaya konulmaya odaklanılmıştır (29). Bunun dışında kişinin yeme alışkanlıklarının da GÖRH oluşmasında etkili olması kuvvetle muhtemeldir. Fakat bu konuda literatür bilgisi oldukça kısıtlıdır. Yuan ve ark.' nın yaptığı GÖRH olan hastalarda yaşam tarzı düzenlenmesine dair ulusal çok merkezli bir çalışmada

Genel Tip Derg 2021;31(4)380-384 
hastalar çok aşırı yemek yeme, hızlı yeme ve çok sıcak yeme gibi yeme alışkanlıkları açısından değerlendirilmiş ve bu yeme tutumları GÖRH açısından risk faktörü olarak tanımlanmıştır (16). Bu çalışma, yeme alışkanlıklarının GÖRH ile ilişkili olabileceğini gündeme getirmesi ve verdiği sonuçlar açısından çok önemlidir fakat bahsedilen çok aşırı yemek yeme, hızlı yeme, çok sıcak yeme gibi tanımlamalar subjektif olarak yapılmış ve buna göre değerlendirmede bulunulmuştur. Bizim çalışmamızda, patolojik yeme davranışına objektif yaklaşabilmek için TYB tanı kriterlerini kullanıldı ve GÖRH olan bireylerde kontrol grubu ile kıyaslandığında TYB' nun anlamlı derecede daha yüksek oranda olduğunu saptadı.

Çalışmamızda, 24 saatlik pH monitörizasyonu ile elde ettiğimiz verilerden reflü periyod sayısı, gün içerisinde özefagusa olan asit reflüyü göstermektedir ve 24 saatte 50 'ye kadar normal kabul edilmektedir (17). Bu değer TYB olan reflü hastalarında ortalama 61,33 , TYB olmayanlarda ise ortalama 55,22 olarak normal sınırın üzerinde bulundu. TYB olanlarda daha yüksek olarak kaydedilmesine rağmen bu fark istatistiki olarak anlamlılık göstermedi. TYB'nda yeme periyotlarında kontrolsüz, aşırı miktarda yeme gibi patolojik davranışlar görülmesine rağmen, yeme sıklığında normal bireyler ile bir farklılık bulunmamaktadır. Bu nedenle reflü periyod sayısının da normal bireyler ile farklılık göstermemesi beklenebilecek bir durumdur.

DeMeester skoru, 24 saatlik $\mathrm{pH}$ monitörizasyonu ile elde edilen veriler kullanılarak oluşturulan bileşik bir skordur. Bu skorun normal üst limiti ise $14,7^{\prime}$ 'dir ve üzerinde çıkan değerler patolojik reflüyü göstermektedir. Çalışmamızda GÖRH nedeniyle 24 saatlik pH monitörizasyonu yapılan ve TYB olan hastalarda bu değer anlamlı olarak daha yüksek bulundu.

24 saatlik $\mathrm{pH}$ monitörizasyon işlemi ile elde ettiğimiz bir diğer veri, gün içindeki toplam reflü zamanıdır ve özefagusa $\mathrm{pH}<4$ olan reflünün toplam zamanın tüm güne yüzdesi ile ifade edilir. Bu değerin 4,2'nin altında olması normal olarak kabul edilir (17). Çalışmamızda bu değerin TYB olan GÖR hastalarında, olmayanlara kıyasla anlamlı oranda daha yüksek olduğunu izledik (toplam reflü zamanı sırasıyla: ortalama 7,22 ve 5,64 ). Gün içerisindeki toplam reflü periyod sayısında bir fark izlenmezken toplam reflü zamanının TYB olan hastalarda anlamlı derecede daha yüksek olması bize reflü periyodlarının daha uzun sürdüğünü göstermektedir. Bu durumu, 24 saatlik pH monitörizasyonu ile elde ettiğimiz uzun reflü periyod sayıs1 ve en uzun reflü epizodu verileri de desteklemektedir. TYB olan hastalarda uzun reflü periyod sayısı (5 dakikadan daha uzun süren reflüleri tariflemektedir), TYB olmayanlara oranla 2 kat daha yüksek bulundu. Ayrıca monitörizasyon ile tespit edilen gün içerisinde kaydedilen en uzun reflü epizodu, TYB olanlarda ortalama 24,33 dk ile anlamlı derecede daha yüksek bulundu. Bu değerin normalde 9,2 dk nın altında olması gerekirken TYB olan reflü hastalarında ortalama yarım saate yaklaşması, özefagusun çok daha uzun sürede asit içeriğe maruz kaldığını göstermektedir.

\section{Sonuc}

GÖRH toplumda sık görülen ve etyolojisinde birçok faktörün rol oynadığı bir hastalıktır. Bu nedenle tedavi planlanırken, hastalığın sebebine yönelik yaklaşımlar ön planda bulundurulmalıdır aksi takdirde tedavide başarısızlık ihtimali artacaktır. Özellikle GÖRH tedavisinde başarısız olunan hastalarda, TYB' nun da akılda bulundurulması, tedavi başarı oranlarını artıracaktır.

\section{Kaynaklar}

1.Dobrucalı A. Gastroözofagial Reflü Hastalığı ve Teșhis ve Tedavide Karșılașılan Sorunlar. Sempozyum Dizisi. 2007;58:9-30.

2.Kahrilas PJ. GERD pathogenesis, pathophysiology, and clinical manifestations. Cleveland Clinic journal of medicine. 2003;70(5):S4

3.Tack J, Becher A, Mulligan C, Johnson D. Systematic review: the burden of disruptive gastro-oesophageal reflux disease on health-related quality of life. Alimentary pharmacology \& therapeutics. 2012;35(11):1257-66.

4.Locke 3rd G, Talley NJ, Fett SL, Zinsmeister AR, Melton 3rd L. Prevalence and clinical spectrum of gastroesophageal reflux: a population-based study in Olmsted County, Minnesota. Gastroenterology. 1997;112(5):1448-56.

5.Flegal KM, Carroll MD, Ogden CL, Johnson CL. Prevalence and trends in obesity among US adults, 1999-2000. Jama. 2002;288(14):1723-7.

6.Kitapcioglu G, Caymaz-Bor C, Gilbert RJ. Gastroesophageal reflux disease in a lowincome region in Turkey. The American journal of gastroenterology. 2005;100(4):759.

7.Turan S, Poyraz C, Ozdemir A. Binge Eating Disorder. Psikiyatride Guncel Yaklasimlar. 2015;7:419-35.

8.Association AP. Diagnostic and statistical manual of mental disorders (DSM-5®): American Psychiatric Pub; 2013

9.Hudson JI, Hiripi E, Pope Jr HG, Kessler RC. The prevalence and correlates of eating disorders in the National Comorbidity Survey Replication. Biological psychiatry. 2007;61(3):348-58.

10.Field AE, Sonneville KR, Micali N, Crosby RD, Swanson SA, Laird NM, et al. Prospective association of common eating disorders and adverse outcomes. Pediatrics. 2012;130(2):e289-e95.

11.Fairburn CG, Cooper Z, Doll HA, Norman P, O'Connor M. The natural course of bulimia nervosa and binge eating disorder in young women. Archives of General psychiatry. 2000;57(7):659-65.

12.Sonneville KR, Horton NJ, Micali N, Crosby RD, Swanson SA, Solmi F, et al. Longitudinal associations between binge eating and overeating and adverse outcomes among adolescents and young adults: does loss of control matter? JAMA pediatrics. 2013;167(2):149-55

13.Olguin P, Fuentes M, Gabler G, Guerdjikova AI, Keck PE, McElroy SL. Medical comorbidity of binge eating disorder. Eating and Weight Disorders-Studies on Anorexia, Bulimia and Obesity. 2017;22(1):13-26.

14.Group CGS. Value of reflux diagnostic questionnaire in the diagnosis of gastroesophageal reflux disease. Chinese Journal of Digestive Diseases. 2004;5(2):51-5.

15.Jones R, Junghard O, Dent J, Vakil N, Halling K, Wernersson B, et al. Development of the GerdQ, a tool for the diagnosis and management of gastro-oesophageal reflux disease in primary care. Alimentary pharmacology \& therapeutics. 2009;30(10):1030-8.

16.Yuan L-Z, Yi P, Wang G-S, Tan S-Y, Huang G-M, Qi L-Z, et al. Lifestyle intervention for gastroesophageal reflux disease: a national multicenter survey of lifestyle factor effects on gastroesophageal reflux disease in China. Therapeutic advances in gastroenterology. 2019;12:1756284819877788.

17.Johnson LF, DeMeester TR. Development of the 24-hour intraesophageal pH monitoring composite scoring system. Journal of clinical gastroenterology. 1986;8:52-8.

18.Buttar NS, Falk GW, editors. Pathogenesis of gastroesophageal reflux and Barrett esophagus. Mayo Clinic Proceedings; 2001: Elsevier.

19.Friedenberg FK, Xanthopoulos M, Foster GD, Richter JE. The association between gastroesophageal reflux disease and obesity. The American journal of gastroenterology. 2008;103(8):2111.

20.Moki F, Kusano M, Mizuide M, Shimoyama Y, Kawamura O, Takagi H, et al. Association between reflux oesophagitis and features of the metabolic syndrome in Japan. Alimentary pharmacology \& therapeutics. 2007;26(7):1069-75 
21. Shepherd KL, James AL, Musk AW, Hunter ML, Hillman DR, Eastwood PR. Gastrooesophageal reflux symptoms are related to the presence and severity of obstructive sleep apnoea. Journal of sleep research. 2011;20(1pt2):241-9.

22.Dore MP, Maragkoudakis E, Fraley K, Pedroni A, Tadeu V, Realdi G, et al. Diet, lifestyle and gender in gastro-esophageal reflux disease. Digestive diseases and sciences. 2008;53(8):2027-32.

23.Labenz J, Kulig M, Leodolter A, Vieth M. Risk factors for erosive esophagitis: a multivariate analysis based on the ProGERD study initiative. The American journal of gastroenterology. 2004;99(9):1652.

24.Nozu T, Komiyama H. Clinical characteristics of asymptomatic esophagitis. Journal of gastroenterology. 2008;43(1):27-31.

25.Bayrakci B, Kasap E, Kitapçioğlu G, Bor S. Low prevalence of erosive esophagitis and Barrett esophagus in a tertiary referral center in Turkey. The Turkish journal of gastroenterology: the official journal of Turkish Society of Gastroenterology. 2008;19(3):145-51.

26.Veugelers P, Porter G, Guernsey D, Casson A. Obesity and lifestyle risk factors for gastroesophageal reflux disease, Barrett esophagus and esophageal adenocarcinoma. Diseases of the Esophagus. 2006;19(5):321-8.

27. Shaheen N, Ransohoff DF. Gastroesophageal reflux, Barrett esophagus, and esophageal cancer: scientific review. Jama. 2002;287(15):1972-81.

28.Ayazi S, Tamhankar A, DeMeester SR, Zehetner J, Wu C, Lipham JC, et al. The impact of gastric distension on the lower esophageal sphincter and its exposure to acid gastric juice. Annals of surgery. 2010;252(1):57-62

29.Newberry C, Lynch K. The role of diet in the development and management of gastroesophageal reflux disease: why we feel the burn. Journal of thoracic disease. 2019;11(Suppl 12):S1594. 